\title{
Lifestyle advice in general practice: rates recalled by patients
}

\author{
Chris Silagy, John Muir, Angela Coulter, Margaret Thorogood, Patricia Yudkin, Liane Roe
}

\begin{abstract}
Objective-To document how often patients with varying cardiovascular risk levels reported receiving lifestyle advice from general practice.

Design-Cross sectional descriptive survey by postal questionnaire.

Setting -5 general practices in Bedfordshire.

Subjects-4941 people aged 35-64 years who had consulted a general practitioner at least once during the 12 months before completing the questionnaire and who subsequently attended for a health check as part of the OXCHECK trial.
\end{abstract}

Main outcome measures-Report of having received advice from a general practitioner or practice nurse about smoking, alcohol consumption, exercise, or diet during the 12 months before completing the questionnaire. Cardiovascular risk assessed by a nurse during structured health check.

Results - The overall reported rate of advice was $27 \%$ for smoking, $4.5 \%$ for exercise, $12 \%$ for diet, and $3 \%$ for alcohol consumption. Those with unhealthy behaviour profile or at increased cardiovascular risk received more advice-for example, $47 \%$ of smokers with a history of cardiovascular disease received advice on smoking. Among those at increased risk, men were more likely than women to receive advice about exercise $(11 \% v 4 \%, p=0.04)$ and alcohol consumption $(10 \% v 4 \%, p=0.007)$, while women received more advice about weight $(17 \% v 23 \%, p<0.001)$. The rate of receiving advice was unaffected by age, marital status, or social class.

Conclusion-The low rate of lifestyle advice reported by patients implies that more preventive advice could be provided in primary care.

\section{Introduction}

Changing risk factors related to lifestyle remains the cornerstone of public health efforts to minimise the burden of cardiovascular disease and many forms of cancer. If primary care is to contribute towards this goal, a two step approach is required. Firstly, patients who are at increased risk of developing cardiovascular disease must be identified. Secondly, where this increased risk is the result of modifiable unhealthy lifestyle, appropriate advice and follow up needs to be offered to encourage behaviour change.

The OXCHECK (Oxford and collaborators health check) trial is investigating the effect of this two step approach in a general practice setting. ${ }^{1}$ Practice nurses are offering health checks to middle aged patients in five practices in Bedfordshire. Appropriate health advice, including advice on the need to modify behaviour, is given when necessary and those at increased risk of disease are prioritised for follow up. The study is a randomised controlled trial of 11090 subjects. The primary end points are changes in the key risk factors: smoking status, blood pressure, blood lipid concentration, and body mass index.

Before the trial started all patients completed a health and lifestyle questionnaire similar to one used previously. ${ }^{2}$ The questionnaire asked patients whether they had received preventive advice about specific. aspects of behaviour during the preceding 12 months $\overrightarrow{\vec{\omega}}$ from either a general practitioner or practice nurse. We assessed the relation between advice reportedly received and four lifestyle factors (smoking, alcohol consumption, diet, and exercise) assessed at the subsequent health check. We aimed at characterising the types of patients who claimed to have received lifestyle advice determining the possible relation between risk factor (including the presence of multiple risk factors) and having received advice.

With the exception of two studies carried out in the $\frac{\text { ? }}{\supset}$ United Kingdom during the mid-1980s, ${ }^{23}$ most $\vec{O}$ attempts to ascertain how often preventive advice is $O$ offered in general practice have been limited to general practitioners documenting their own advice rate, ${ }^{4.7}$ audit of records, ${ }^{8-10}$ and small series of videotaped consultations. ${ }^{11}$ Interpreting and comparing results $\vec{\theta}$ from these approaches is difficult. For example, the $N$ recording of advice offered during a general practice consultation in the patient's notes is notoriously poor. ${ }^{51112}$

Studies which use videotaping provide more reliable information about the nature of advice given than audits of records. ${ }^{11}$ However, they are capable only of $\underset{F}{\overrightarrow{7}}$ providing a point prevalence of advice rates in a cross $\frac{3}{3}$ section of consultations and (to date) are limited to $\vec{\partial}$ small numbers of patients. Since general practitioners offer most advice opportunistically in the process of providing continuing care, estimates of advice rates from videotaped consultations are likely to be extremely conservative.

\section{Subjects and methods}

We analysed baseline data obtained from partici- 윽 pants in the OXCHECK trial. The method of the main $N$ study has been reported.' Briefly, a health and lifestyle $D$ questionnaire was mailed to 17965 people aged $35-64$ 으․ registered with five general practices in Luton and N Dunstable, Bedfordshire, during January to July 1989. N Most of the questions had been used in a previous $\sigma$ study. ${ }^{2}$ To these were added the Rose chest pain and claudication questionnaires. ${ }^{13} \mathrm{~A}$ few additional questions about attitudes to behaviour modification $\cong$ were also included. For each of the four aspects of 0 behaviour examined (smoking, diet, exercise, and 0 alcohol consumption) there was a specific question: "In the last 12 months has a doctor or nurse advised you to $\mathbb{D}$ take more exercise/stop smoking/drink less alcohol/ change your diet or lose weight?"

The estimated response rate for completion of the 8 questionnaire was $80 \cdot 3 \% .^{1}$ All respondents $(n=11090)$ were then randomised to be offered a health check during one of four years beginning in mid-1989. By? 1 March 1992 data on risk factors were available for the first 5803 subjects who had attended an initial health check. Of these, 862 stated that they had not visited a 
general practice during the 12 months before receiving the health and lifestyle questionnaire. These patients were excluded as this would have prevented them from receiving any advice, leaving 4941 people for analysis.

Eight possible cardiovascular risk factors were identified at the time of the health check: reported history of ischaemic heart disease, angina, stroke, or transient ischaemic episodes; reported family history of ischaemic heart disease, angina, stroke, or transient ischaemic episodes in a first degree relative before the age of 60 ; history of high blood pressure requiring drug treatment; history of diabetes mellitus requiring treatment; current smoker; high dietary fat intake; physical inactivity; and obesity (body mass index $>25 \mathrm{~kg} / \mathrm{m}^{2}$ ).

Dietary fat intake was classified as high, medium, or low based on a score derived from the reported frequency of intake of 11 food groups which account for about $75 \%$ of the fat in the average British diet. A high dietary fat score corresponded to an estimated intake greater than $110 \mathrm{~g} /$ day. This would be equivalent to a fat intake of $45 \%$ of energy on a $9.2 \mathrm{MJ}$ diet, which is well above the $35 \%$ recommended in the COMA report. ${ }^{1 .}$

Exercise gradings were based on reported leisure time and work activity. Patients were defined as inactive if they (a) undertook no physical activity during work hours and $(b)$ undertook vigorous leisure activity (such as football, jogging, cycling, or swimming) less than once a month and (c) undertook less vigorous exercise (such as walking, gardening, or golf) twice a week or less. Those who undertook vigorous activity during work hours or at least once a week during their leisure time were regarded as being active. All other patients were classified as moderately active.

Alcohol consumption was graded according to the reported weekly intake of standard units of alcohol. Excessive drinking was defined as 21 or more units for men and 14 or more units for women. Smokers were classified as non-smokers (which included former smokers), light smokers (fewer than 15 cigarettes or 10 cigars a day), or heavy smokers (15 or more cigarettes or 10 or more cigars a day). Data were also collected on

TABLE I-Numbers (percentages) of patients reporting receiving advice from general practitioners or nurses about common lifestyle behaviours

\begin{tabular}{|c|c|c|c|c|c|}
\hline \multirow[b]{2}{*}{ Risk category } & \multirow{2}{*}{$\begin{array}{l}\text { No of } \\
\text { patients }\end{array}$} & \multicolumn{4}{|c|}{ No $(\%)$ of patients receiving advice on: } \\
\hline & & Smoking $\star$ & Exercise & Diet & Alcoholt \\
\hline \multicolumn{6}{|l|}{ Smoking: } \\
\hline Light & 853 & $187(22 \cdot 2)$ & $39(4 \cdot 7)$ & $78(9 \cdot 2)$ & $28(5 \cdot 5)$ \\
\hline Heavy & 482 & $172(35.9)$ & $17(3 \cdot 6)$ & $60(12 \cdot 6)$ & $16(5 \cdot 8)$ \\
\hline \multicolumn{6}{|l|}{ Exercise: } \\
\hline Active & 1380 & $75(25 \cdot 6)$ & $44(3 \cdot 3)$ & $150(10.9)$ & $25(2 \cdot 9)$ \\
\hline Moderately active & 3089 & $297(27 \cdot 6)$ & $144(4 \cdot 8)$ & $372(12 \cdot 2)$ & $49(2.9)$ \\
\hline Inactive & 472 & $37(27 \cdot 8)$ & $34(7 \cdot 3)$ & $76(16 \cdot 2)$ & $13(4 \cdot 9)$ \\
\hline \multicolumn{6}{|c|}{ Alcohol consumption‡: } \\
\hline Low or moderate & 2205 & $136(26 \cdot 7)$ & $87(4 \cdot 1)$ & $230(10 \cdot 5)$ & $37(1 \cdot 7)$ \\
\hline High & 654 & $73(27 \cdot 1)$ & $37(5 \cdot 7)$ & $76(11.7)$ & $50(7 \cdot 7)$ \\
\hline \multicolumn{6}{|l|}{ Total fat intake: } \\
\hline Low & 2036 & $124(27 \cdot 2)$ & $99(4 \cdot 9)$ & $321(16 \cdot 0)$ & $40(3 \cdot 5)$ \\
\hline Moderate & 1647 & $123(28 \cdot 0)$ & $73(4 \cdot 5)$ & $167(10 \cdot 2)$ & $19(2 \cdot 0)$ \\
\hline High & 1258 & $112(26 \cdot 4)$ & $50(4 \cdot 1)$ & $110(8 \cdot 8)$ & $28(3 \cdot 8)$ \\
\hline \multicolumn{6}{|c|}{ Obesity (body mass index $\mathrm{kg} / \mathrm{m}^{2}$ ): } \\
\hline$<24$ & 2326 & $176(25.9)$ & $56(2 \cdot 5)$ & $72(3 \cdot 1)$ & $30(2 \cdot 2)$ \\
\hline $25-29$ & 1924 & $132(27 \cdot 1)$ & $88(4 \cdot 7)$ & $237(12 \cdot 4)$ & $41(3.5)$ \\
\hline$\geqslant 30$ & 687 & $51(33 \cdot 4)$ & $78(11 \cdot 7)$ & $289(42.5)$ & $16(5 \cdot 0)$ \\
\hline \multicolumn{6}{|c|}{ Treatment for high blood pressure: } \\
\hline Yes & 682 & $64(42 \cdot 1)$ & $60(9 \cdot 0)$ & $197(29 \cdot 3)$ & $22(6 \cdot 2)$ \\
\hline No & 4259 & $295(25.3)$ & $162(3.9)$ & $401(9 \cdot 5)$ & $65(2 \cdot 6)$ \\
\hline \multicolumn{6}{|c|}{ Family history of cardiovascular disease: } \\
\hline Yes & 835 & $77(33 \cdot 2)$ & $43(5 \cdot 3)$ & $127(15 \cdot 3)$ & $16(3 \cdot 0)$ \\
\hline No & 4106 & $282(25 \cdot 9)$ & $179(4 \cdot 5)$ & $471(11 \cdot 6)$ & $71(3 \cdot 4)$ \\
\hline \multicolumn{6}{|c|}{ History of cardiovascular disease: } \\
\hline Yes & 208 & $27(47 \cdot 4)$ & $25(12 \cdot 5)$ & $60(29 \cdot 3)$ & $10(8 \cdot 6)$ \\
\hline No & 4733 & $332(26 \cdot 3)$ & $197(4 \cdot 3)$ & $538(11 \cdot 5)$ & $77(2 \cdot 8)$ \\
\hline \multicolumn{6}{|c|}{ Treatment for diabetes: } \\
\hline Yes & 101 & $13(50 \cdot 0)$ & $12(12 \cdot 1)$ & $54(55 \cdot 7)$ & $5(14 \cdot 3)$ \\
\hline No & 4840 & $346(26 \cdot 7)$ & $210(4 \cdot 4)$ & $544(11 \cdot 3)$ & $82(2 \cdot 9)$ \\
\hline All patients & 4941 & $359(27 \cdot 2)$ & $222(4 \cdot 5)$ & $598(12 \cdot 1)$ & $87(3 \cdot 1) \ddagger$ \\
\hline
\end{tabular}

*Proportions are only of smokers $(n=1335)$.

tProportions are only of people who consumed at least some alcohol $(n=2859)$

$\ddagger$ Low or moderate $=<21$ units a week (men) or $<14$ units a week (women); high $=\geqslant 21$ units a week (men) or $\geqslant 14$ units a week (women)

A few patients did not respond to all questions. social and demographic characteristics including age, sex, marital status, and social class. ${ }^{15}$

The data were analysed with SAS-PC statistical software. To establish whether increasing risk levels were associated with a change in the likelihood of receiving advice about modifying behaviour $\chi^{2}$ tests for trend were done. ${ }^{16}$ All $p$ values quoted are two tailed.

\section{Results}

Table I shows the proportions of patients who reported being offered advice about smoking, exercise, diet, and alcohol consumption in the 12 months before completing the questionnaire, both overall and according to health risks. Smoking was the behaviour most likely to attract advice from a health professional, although just $27 \%$ of smokers reported receiving advice. The proportions of smokers with a history of diabetes, cardiovascular disease, or high blood pressure requiring treatment who received advice about smoking was higher, but never more than $50 \%$.

The proportion of people receiving advice about exercise and diet was significantly higher among those who were overweight, diabetic, or hypertensive or who had a history of cardiovascular disease $(\mathrm{p}<0.001$ in all cases). Overall, only $4.5 \%$ of patients received advice about exercise, but the proportion increased as the level of activity decreased $\left(\chi^{2}\right.$ for trend $13 \cdot 1, \mathrm{df}=1$; $\mathrm{p}<0.001)$

Dietary advice was received by $12 \%$ of patients. The proportion rose with increasing obesity $\left(\chi^{2}\right.$ for trend $659, \mathrm{df}=1 ; \mathrm{p}<0.001)$ and as the amount of exercise decreased $\left(\chi^{2}\right.$ for trend $\left.7 \cdot 3, \mathrm{df}=1 ; \mathrm{p}=0 \cdot 007\right)$. It fell significantly, however, as the reported fat intake increased ( $\chi^{2}$ for trend $41.5, \mathrm{df}=1 ; \mathrm{p}<0.001$ ).

Advice about alcohol consumption was reportedly offered less often than that on any of the other lifestyle behaviours. Even among those with a heavy intake only $8 \%$ reported receiving advice.

The percentage of patients who were offered lifestyle advice rose significantly with the total number of risk factors present (table II). But even among those at highest risk (with three or more risk factors), the rate of advice. was still low. For example, only one third of current smokers in this category were advised about smoking; $24 \%$ received dietary advice and $9 \%$ advice about exercise.

Table III shows the relation between receiving advice and sociodemographic characteristics among the population at risk. Men were significantly more likely than women to receive advice about exercise $\left(\chi^{2}=8.3, \mathrm{df}=1 ; \mathrm{p}=0.004\right)$ and alcohol consumption $\left(\chi^{2}=7 \cdot 2, \mathrm{df}=1 ; \mathrm{p}=0.007\right)$. In contrast, overweight women were more likely to receive dietary advice than overweight men $\left(\chi^{2}=16.9, \mathrm{df}=1 ; \mathrm{p}<0.001\right)$. Marital status, social class, and age were not significantly associated with the likelihood of receiving advice.

\section{Discussion}

Our results suggest that the frequency with which patients recall having received lifestyle advice from general practitioners or practice nurses is extremely low. This is of concern since general practice offers ideal opportunities to advise patients about the health risks associated with lifestyle and provide strategies to modify them. ${ }^{17}$ Over $80 \%$ of the subjects in the OXCHECK trial reported visiting their general practitioner at least once during the year before the questionnaire. This rate is consistent with previously reported figures. ${ }^{18}$ For those at increased risk, such as smokers or those who consume large quantities of alcohol, this may be a conservative estimate of the consultation rate. Furthermore, most people regard their general practitioner and practice nurse as being 
TABLE II-Numbers (percentages) of patients reporting having received advice from general practitioners or nurses about common lifestyle behaviours according to number of cardiovascular risk factors

\begin{tabular}{|c|c|c|c|c|c|}
\hline \multirow{2}{*}{$\begin{array}{l}\text { No of cardiovascular } \\
\text { risk factors }\end{array}$} & \multirow{2}{*}{$\begin{array}{l}\text { No of } \\
\text { patients }\end{array}$} & \multicolumn{4}{|c|}{ No (\%) of patients receiving advice on: } \\
\hline & & Smoking ${ }^{\star}$ & Exercise & Diet & Alcohol $\dagger$ \\
\hline 0 & 874 & N/A $\ddagger$ & $18(2 \cdot 1)$ & $18(2 \cdot 1)$ & $6(1 \cdot 1)$ \\
\hline 1 & 1729 & $62(21 \cdot 5)$ & $61(3 \cdot 6)$ & $164(9 \cdot 6)$ & $12(1 \cdot 2)$ \\
\hline 2 & 1490 & $144(25 \cdot 7)$ & $70(4 \cdot 8)$ & $212(14 \cdot 3)$ & $35(4 \cdot 1)$ \\
\hline$\geqslant 3$ & 848 & $153(32.4)$ & $73(8 \cdot 8)$ & $204(24 \cdot 3)$ & $34(7 \cdot 4)$ \\
\hline$\chi^{2}$ for trend $(d f=1)$ & & 11.5 & $44 \cdot 5$ & $209 \cdot 2$ & $42 \cdot 6$ \\
\hline p Value & & $<0.001$ & $<0.001$ & $<0.001$ & $<0.001$ \\
\hline
\end{tabular}

*Proportions are only of smokers $(n=1335)$

†Proportions are of people who consumed at least some alcohol $(n=2859)$.

$\ddagger$ Not applicable since all smokers by definition have at least one risk factor.

A few patients did not respond to all questions.

TABLE III-Numbers (percentages) of patients with cardiovascular risk factors who received lifestyle advice according to sociodemographic characteristics

\begin{tabular}{|c|c|c|c|c|c|}
\hline & \multicolumn{5}{|c|}{ No (\%) of patients ${ }^{\star}$ receiving advice on: } \\
\hline & $\begin{array}{l}\text { Smoking } \\
(n=1355)\end{array}$ & $\begin{array}{l}\text { Exercise } \\
(n=472)\end{array}$ & $\begin{array}{l}\text { Diet (weight) } \\
(\mathrm{n}=2611)\end{array}$ & $\begin{array}{l}\text { Diet (fat) } \\
(n=1258)\end{array}$ & $\begin{array}{l}\text { Alcohol } \\
(n=654)\end{array}$ \\
\hline \multicolumn{6}{|l|}{ Sex: } \\
\hline Male & $163(26 \cdot 3)$ & $24(11 \cdot 0)$ & $196(16 \cdot 7)$ & $61(8 \cdot 5)$ & $41(9 \cdot 8)$ \\
\hline Female & $196(28.0)$ & $10(4 \cdot 1)$ & $330(23 \cdot 2)$ & $49(9 \cdot 1)$ & $9(3.9)$ \\
\hline \multicolumn{6}{|l|}{ Age (years) } \\
\hline $35-44$ & $119(23.5)$ & $13(6 \cdot 9)$ & $156(19 \cdot 1)$ & $31(6 \cdot 7)$ & $20(7 \cdot 4)$ \\
\hline $45-54$ & $147(32 \cdot 7)$ & $13(8.0)$ & $190(21 \cdot 6)$ & $39(10 \cdot 6)$ & $12(5 \cdot 1)$ \\
\hline $55-64$ & $93(25 \cdot 6)$ & $8(7 \cdot 1)$ & $180(20 \cdot 1)$ & $40(9 \cdot 4)$ & $18(12 \cdot 7)$ \\
\hline \multicolumn{6}{|l|}{ Marital status $\dagger$} \\
\hline Married or cohabiting & $261(26 \cdot 2)$ & $28(7: 4)$ & $409(19.5)$ & $82(8 \cdot 1)$ & $37(7 \cdot 4)$ \\
\hline Widowed & $20(23.5)$ & & $23(18 \cdot 1)$ & $6(10 \cdot 7)$ & \\
\hline Divorced or separated & $53(36 \cdot 6)$ & $2(5 \cdot 1)$ & $44(24 \cdot 6)$ & $9(9 \cdot 4)$ & $6(9 \cdot 0)$ \\
\hline Single & $17(25 \cdot 8)$ & $3(10 \cdot 0)$ & $36(26 \cdot 3)$ & $10(13 \cdot 7)$ & $6(12 \cdot 2)$ \\
\hline \multicolumn{6}{|l|}{ Social class } \\
\hline I/II & $69(27 \cdot 3)$ & $11(8 \cdot 2)$ & $118(19 \cdot 6)$ & $14(5 \cdot 8)$ & $21(11 \cdot 4)$ \\
\hline IIIN & $70(25 \cdot 2)$ & $7(4 \cdot 4)$ & $121(21 \cdot 6)$ & $19(7 \cdot 9)$ & $4(3 \cdot 2)$ \\
\hline IIIM & $63(25 \cdot 2)$ & $6(9 \cdot 0)$ & $97(19 \cdot 2)$ & $33(11 \cdot 1)$ & $13(8 \cdot 5)$ \\
\hline IV/V & $80(26.9)$ & $5(8 \cdot 8)$ & $92(20.9)$ & $26(10 \cdot 0)$ & $7(6: 7)$ \\
\hline Unclassified & $77(32.0)$ & $5(10 \cdot 4)$ & $98(20 \cdot 3)$ & $18(8.5)$ & $5(6 \cdot 3)$ \\
\hline
\end{tabular}

${ }^{\star}$ For each category only those at risk are included: smokers, people who were inactive, people with body mass index $\geqslant 25 \mathrm{~kg} / \mathrm{m}^{2}$, people with high total fat intake, and heavy drinkers respectively.

† Marital status was not known for 85 people.

$\ddagger$ Includes students, housewives, and those who left the question blank.

credible sources of health information, even if they subsequently elect not to follow the advice given. ${ }^{19}$

The rate at which preventive advice was reportedly offered by general practitioners or nurses in our study was almost identical with that reported from the Oxford region by Coulter ${ }^{2}$ and from the Medical Research Council's general practice research framework. ${ }^{3}$ The results are also similar to those in studies that have used different methods to assess preventive advice in primary care. ${ }^{20}$ This is disappointing given the strong push in recent years from government, public health authorities, and the Royal College of General Practitioners to increase the level of preventive activity in general practice. ${ }^{21-23}$

WHY ARE ADVICE RATES LOW?

Part of the explanation for the low advice rates observed in this study may be underreporting by patients, either because they forgot that advice was offered or because they failed to recognise that advice was being given. Forgetting advice is unlikely as research suggests that patients who receive advice from their general practitioner usually have a high recall even many years later. ${ }^{20}$ Failure to recognise advice may be more of a problem since often only a passing reference will be made in a consultation about the need to modify behaviour. Whether patients perceived this as advice will vary.

A further explanation of the low advice rates may be the failure of general practitioners to appreciate that a patient was at increased risk. This is particularly applicable for alcohol consumption, where the rate of detection of heavy drinkers is often poor, ${ }^{24}$ and for dietary advice to those with high fat intake, since most general practitioners or practice nurses do not routinely assess diet. ${ }^{5}$

The time difference between completing the lifestyle questionnaire and attending the health check for an objective risk assessment, in some cases as much as two and a half years, may also have been a problem. Some people who were healthy at the time of completing the initial questionnaire, and therefore did not warrant lifestyle advice, may have developed unhealthy risk profiles before their health check. There is no obvious reason why such an unhealthy change would occur in a large proportion of OXCHECK subjects.

\section{APPROPRIATENESS OF ADVICE}

In any consideration of preventive health care in general practice it is important to distinguish the frequency of lifestyle advice from the appropriateness and quality of such advice. In general practice it is neither necessary nor desirable for all patients to receive advice about specific lifestyle risk factors. ${ }^{2025}$ The important issue is that general practitioners can identify patients who are most at risk from a particular lifestyle factor and therefore stand to benefit the most from any lifestyle advice. Attempting to achieve advice rates of $100 \%$ for each factor in all patients may cause unnecessary anxiety and produce a group of worried well patients. ${ }^{20} 2627$

The time or setting of some consultations may make raising lifestyle issues inappropriate-for example, an emergency home visit. Stott and Pill highlight the fact that lifestyle advice is acceptable only if it is seen to be directly related to the presenting problem. ${ }^{28}$ We could not explore this finding further because no data were collected on the nature of the consultation(s) at which advice could have been offered. Since some of these consultations would probably have been inappropriate for offering lifestyle advice the denominator of available opportunities used in this study is probably a slight overestimate.

We have no information on the quality of advice offered. Although this is likely to vary, previous research has indicated that even simple advice can be effective in altering behaviour. ${ }^{29}{ }^{30}$ If a patient can recall receiving some advice about a lifestyle factor there is an increased chance of modified behaviour.

\section{WHO RECEIVED MOST ADVICE?}

Despite these limitations comparisons can be made between the rates of advice for the different lifestyle factors and for different levels of overall risk. Advice was offered less often about exercise and alcohol than about smoking or diet. Two factors may account for this. Firstly, both smoking and diet have been higher on the public health agenda in recent years and, secondly, there are more resources available to assist general practitioners in providing antismoking advice or nutritional advice than for advice about alcohol or exercise. Advice about smoking, diet, and alcohol intake was offered more often to patients with more risk factors, but this was not true for advice about exercise. Clearly, further effort is needed to increase awareness of inactivity as a modifiable cardiovascular risk factor. An increased awareness of the additional risk associated with a family history of cardiovascular disease is also required since this ought to be a further prompt for the need for lifestyle advice.

Although nutritional advice was commonly given when people were overweight, there was an inverse relation between total fat intake and the receipt of dietary advice. This is surprising and may reflect a heightened interest in obtaining advice among those who already consume a healthy diet. Alternatively, people with poor diets may be less likely to recall receiving dietary advice. A high total fat intake need not be associated with obesity and yet it places an individual at increased cardiovascular risk. Assessment of dietary intake, and provision of appropriate advice if needed, is therefore as important as assessing 
body mass index and counselling for weight reduction.

Advice about exercise and alcohol consumption was more commonly reported by men at risk than women. Conversely, more overweight women reported receiving advice about diet than did overweight men. This may reflect association of specific lifestyle behaviours with gender by general practitioners, most of whom were men. Overweight women may be more likely to ask about diet. No gender effect was seen for receiving dietary advice when the risk criterion was fat intake rather than obesity.

SUMMARY

In conclusion, patients recalled a low rate of receiving lifestyle advice from a general practitioner or practice nurse. The rate was particularly low among those at risk from excessive alcohol consumption or inactivity. Although the accuracy of our estimate is limited by methodological problems, there is still considerable room for increasing preventive activity. The final results from the OXCHECK trial, expected in 1993, will provide information on whether nurse based identification of individuals at risk and subsequent lifestyle advice is an effective method of achieving this.

We thank the Imperial Cancer Research Fund OXCHECK study group for access to the data; Drs D Mant and G Fowler for technical advice; and Dr J Russell for reading the manuscript. CS is the 1991-2 Sir Robert Menzies Memorial Scholar in Medicine for Australia, funded by the Menzies Trust.

1 Imperial Cancer Research Fund OXCHECK Study Group. Prevalence of risk factors for heart disease in OXCHECK trial: implications for screening in primary care. BMF 1991;302:1057-60.

2 Coulter A. Lifestyles and social class: implications for primary care. $f \mathrm{R} \mathrm{Coll}$ Gen Pract 1987;37:533-6.

3 Wallace PG, Brennan PJ, Haines AP. Are general practitioners doing enough to promote healthy lifestyle? Findings of the Medical Research Council's general practice research framework study on lifestyle and health. $B M \mathcal{J}$ 1987;294:940-2

4 Carford JC, Nutbeam D. Prevention in practice: what Wessex general practitioners are doing. BMF 1984;288:832-4

5 Coulter A Schofield T. Prevention in general practice: the views of doctors in the Oxford region. Br 7 Gen Pract 1991;41:140-3.
6 Orleans CT, George LK, Houpt JL, Brodie KH. Health promotion in primary care: a survey of US family practitioners. Prev Med 1985;14:636-47.

7 Ford AS, Ford WS. Health education and the primary care physician: the practitioner's perspective. Soc Sci Med 1983;17:1505-12.

8 Lawrence $M$, Coulter A, Jones L. A total audit of preventive procedures in 45 practices caring for 430000 patients. $B M^{7} 1990 ; 300: 1501-3$.

9 Fleming DM, Lawrence MS. An evaluation of recorded information about preventive measures in 38 practices. $f$ R Coll Gen Pract 1981;31:615-20.

10 Fleming DM, Lawrence MS. Impact of audit on preventive measures. BMF 1983;287:1852-4.

11 Dickinson JA, Wiggers J, Leeder SR, Sanson-Fisher RW. General practitioners' detection of patients' smoking status. Med f Aust 1989;150: $420-6$

12 Freeling P, Littlejohns $\mathbf{P}$. Counselling cigarette smokers in general practice. Maternal and Child Health 1989;14:394-7.

13 Rose G, McCartney P, Reid D. Self administration of a questionnaire on chest pain and intermittent claudication. Br $\mathcal{F}$ Prev Soc Med 1977;31:42-8.

14 Committee on Medical Aspects of Food Policy. Diet and cardiovascular disease. Report on health and social subjects 28. London: HMSO, 1984

15 Office of Population Censuses and Surveys. Classification of occupation London: HMSO, 1980.

16 Armitage P, Berry G. Statistical methods in medical research. 2nd ed. Oxford: Blackwell, 1987:372-4.

17 Stott $\mathrm{NCH}$, Davis $\mathrm{RH}$. The exceptional potential in each primary care consultation. I R Coll Gen Pract 1979;29:201-5.

18 Freer CB, Boyle P, Ryan MP. A study of attendance patterns in general practice over three years. Health Bull 1986;44:75-80.

19 Fullard E, Fowler G, Gray M. Facilitating prevention in primary care. $B M \mathcal{Y}$ $1984 ; 297: 1585-7$

20 Pill RM, Jones-Elwyn G, Stott NCH. Opportunistic health promotion: quantity or quality? I $R$ Coll Gen Pract 1989;39:196-200.

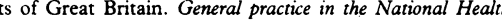
Service: the 1990 contract. London: HMSO, 1989.

22 Stone DH. Primary care, community medicine and prevention: a convergen of needs. $7 R$ Coll Gen Pract 1987;37:218-20.

23 Royal College of General Practitioners. Health and prevention in primary care. London: RCGP, 1981. (Report from general practice 18.)

24 Fullard E, Fowler G, Gray M. Promoting prevention in primary care: controlled trial of low technology, low cost approach. BMF 1987;294: $1080-2$

25 Tuckett D, Boulton M, Olson C, Williams A. Meetings between experts: approach to sharing ideas in medical consultations. London: Tavistock, 1985.

26 Pill R, French J, Harding K, Stott N. Invitation to attend a health check in general practice setting: comparison of attenders and non-attenders. $\exists R$ Coll Gen Pract 1988;38:53-6.

27 Stoate HG. Can health screening damage your health. $f R$ Coll Gen Prect 1989;39:193-5.

8 Stott NCH, Pill RM. "Advise yes, dictate, no." Patients' views on health promotion in the consultation. Fam Pract 1990;7:125-31.

29 Jamrozik K, Vessey $M$, Fowler G, Wald N, Parker G, Van-Vunakis $H$. Controiled trial of three different antismoking interventions in general practice. BMf 1984;288: 1499-503.

30 Russell MA, Stapelton JA, Jackson PH, Hajek P, Belcher M. District programme to reduce smoking: effect of clinic supported brief intervention by general practitioners. $B M \mathcal{F} 1987 ; 295: 1240-4$.

(Accepted 8 September 1992)

\section{ANY QUESTIONS}

How should patients who develop Parkinson's disease be managed if they need to continue to take monoamine oxidase $A$ inhibitors?

Levodopa, the most effective treatment for Parkinson's disease, cannot be used in patients receiving non-selective or type A monoamine oxidase inhibitors because of the potential risk of appreciable rises in blood pressure.' In animal studies this pressor response can be blocked by large doses of peripheral dopa decarboxylase inhibitors, but attempts to combine levodopa, non-selective monoamine oxidase inhibitors, and high doses of dopa decarboxylase inhibitors in patients with Parkinson's disease led to unacceptable breakthrough hypertension. ${ }^{2}$ Dopamine is converted to noradrenaline, which is a type A substrate for monoamine oxidase. On the other hand, dopamine seems to be predominantly a type B substrate; this explains why selegiline hydrochloride, the type B monoamine oxidase inhibitor, can be given usefully in combination with levodopa, increasing its effect by preventing dopamine breakdown in the central nervous system.

The dopamine receptor agonists bromocriptine and pergolide may be used safely with monoamine oxidase type A inhibitors, and although their strength is less than that occurring with optimum doses of levodopa, substantial improvement in parkinsonian disabilities may occur. Considerable care needs to be taken in cautiously building up the dose of agonist if therapeutic effects are to be obtained. If gastrointestinal effects or dizziness occur domperidone, the peripheral dopamine receptor or antagonist, should be given concurrently in a dose of $20 \mathrm{mg}$ three times a day before meals. Amantadine and anticholinergic drugs are other therapeutic strategies, but in most patients their therapeutic effects are less than those that can be obtained with a dopamine agonist.

Finally, whether the patient needs to continue with a monoamine oxidase type $\mathrm{A}$ inhibitor should be considered carefully in each case. Depression, for example, may be the first sign of Parkinson's disease and may improve with dopaminergic treatment. Furthermore, a switch to a tetracyclic antidepressant or selegiline hydrochloride 20 to $30 \mathrm{mg}$ a day might be an effective alternative strategy for treating the depression. If it is decided to withdraw the monoamine oxidase inhibitor at least 14 days should elapse before levodopa is started.-ANDREW LEES, consultant neurologist, London

1 Hunter KR, Boakes AJ, Lawrence DR, Stern GM. Monoamine oxidase inhibitors and L-dopa. $B M F$ 1970;iii:388.

2 Teychenne PF, Calne DB, Lewis PJ, Findley LJ. Interactions of L-dopa with inhibitors of MAO plus 1-aromatic amino-acid decarboxylase. Clin with inhibitors of MAO plus 1 